\title{
Decreased non-esterified fatty acid suppression and features of the insulin resistance syndrome occur in a sub-group of individuals with normal glucose tolerance
}

\author{
C.D. Byrne ${ }^{1}$, N. J. Wareham ${ }^{2}$, N.E. Day ${ }^{2}$, R. McLeish ${ }^{1}$, D. R.R. Williams ${ }^{2}$, C. N. Hales ${ }^{1}$ \\ ${ }^{1}$ University Department of Clinical Biochemistry, Addenbrookes Hospital, Cambridge, UK \\ ${ }^{2}$ Department of Community Medicine, Institute of Public Health, University of Cambridge, Cambridge, UK
}

\begin{abstract}
Summary To investigate causes of increased triglyceride concentrations in subjects with normal glucose tolerance (determined by oral glucose tolerance testing using World Health Organization criteria) 883 healthy subjects ( 389 men and 494 women) between 40 and 65 years of age were studied. Subjects were divided by gender into four groups according to 120 min glucose concentrations. Individuals in the highest quartile of glucose concentration had the highest mean triglyceride concentrations $(p<0.0001)$ and highest mean non-esterified fatty acid (NEFA) concentrations $(p<0.0001)$. There was also a clustering of cardiovascular risk factors normally associated with the insulin resistance syndrome in subjects in this group. Regression analysis showed that the most
\end{abstract}

important determinants of triglyceride levels were smoking (men $p=0.001$, women $p=0.005$ ), waist:hip ratio (men $p=0.01$, women $p<0.001$ ) and NEFA suppression (men $p=0.02$, women $p=0.005$ ). NEFAs suppressed $16.7 \%$ in women compared to $2.4 \%$ in men during the first $30 \mathrm{~min}$ of the oral glucose tolerance test $(p<0.001)$. These results show that a clustering of cardiovascular risk factors associated with decreased NEFA suppression occurs in a sub-group of subjects with normal glucose tolerance and that the pattern of NEFA suppression differs between men and women. [Diabetologia (1995) 38: 1358-1366]

Key words Hypertriglyceridaemia, non-esterified fatty acid, ischaemic heart disease, smoking.
Increased plasma triglyceride and decreased plasma high density lipoprotein (HDL) concentrations are cardinal features of the dyslipidaemia associated with the insulin resistance syndrome (IRS) [1]. Abnormalities of these lipids may have important implications for the pathogenesis of ischaemic heart disease (IHD) both in subjects with NIDDM $[2,3]$ and in subjects with normal glucose tolerance [4]. Although it has been shown that hypertriglyceridaemia often occurs in association with hyperinsulinaemia and sev-

Received: 6 March 1995 and in revised form: 17 May 1995

Corresponding author: Dr. C.D. Byrne, Department of Clinical Biochemistry, Addenbrookes Hospital, Hills Road, Cambridge CB2 2QQ, UK

Abbreviations: NEFA, Non-esterified fatty acids; IHD, ischaemic heart disease; HDL, high density lipoprotein; IRS, insulin resistance syndrome; VLDL, very low density lipoprotein; OGTT, oral glucose tolerance test; NIDDM, non-insulin-dependent diabetes mellitus; WHR, waist-hip ratio. eral of the other features of the IRS [5], little is known about the mechanisms causing abnormal triglyceride concentrations in subjects with normal glucose tolerance in the absence of inherited disorders of lipoprotein metabolism. Most of the triglyceride in the circulation in the fasting state originates from the very low density lipoprotein (VLDL) particles and both insulin and non-esterified fatty acids (NEFAs) have been shown by in vitro studies to markedly affect hepatic triglyceride secretion [6-9]. Whether hyperinsulinaemia per se causes hypertriglyceridaemia is still uncertain although, by contrast, NEFAs have been shown to be an important substrate and stimulus to hepatic triglyceride secretion. Inadequate suppression of NEFAs is associated with increased triglyceride concentrations and in vitro data support the notion that, in vivo, increased NEFAs may result in increased fasting triglyceride concentrations $[10,11]$. Smoking is also associated with increased triglyceride concentrations and the immediate effect of smoking is to in- 
Table 1. Anthropometric and biochemical characteristics of subjects grouped by gender and 120-min plasma glucose level

\begin{tabular}{|c|c|c|c|c|c|c|}
\hline & \multirow{2}{*}{$\begin{array}{l}\text { Sex } \\
\text { M, male } \\
\text { F, female }\end{array}$} & \multicolumn{4}{|c|}{ Plasma glucose group (mmol/1) } & \multirow{2}{*}{$\begin{array}{l}p \text { value } \\
\text { for trend }\end{array}$} \\
\hline & & $<5$ & $5-5.69$ & $5.7-6.49$ & $\geq 6.5$ & \\
\hline Number of subjects & $\begin{array}{l}\mathrm{M} \\
\mathrm{F}\end{array}$ & $\begin{array}{r}98 \\
106\end{array}$ & $\begin{array}{r}76 \\
121\end{array}$ & $\begin{array}{r}98 \\
128\end{array}$ & $\begin{array}{l}114 \\
135\end{array}$ & \\
\hline Age (years) & $\begin{array}{l}\mathrm{M} \\
\mathrm{F}\end{array}$ & $\begin{array}{l}52.7 \pm 8.1 \\
51.0 \pm 7.6\end{array}$ & $\begin{array}{l}52.8 \pm 7.5 \\
51.8 \pm 7.4\end{array}$ & $\begin{array}{l}54.8 \pm 8.1 \\
53.3 \pm 7.2\end{array}$ & $\begin{array}{l}54.3 \pm 7.5 \\
54.1 \pm 7.7\end{array}$ & $\begin{array}{l}\text { NS } \\
0.0005\end{array}$ \\
\hline Waist-hip ratio & $\begin{array}{l}\mathrm{M} \\
\mathrm{F}\end{array}$ & $\begin{array}{l}0.89 \pm 0.06 \\
0.75 \pm 0.05\end{array}$ & $\begin{array}{l}0.89 \pm 0.06 \\
0.75 \pm 0.05\end{array}$ & $\begin{array}{l}0.90 \pm 0.06 \\
0.77 \pm 0.06\end{array}$ & $\begin{array}{l}0.91 \pm 0.06 \\
0.77 \pm 0.05\end{array}$ & $\begin{array}{l}\text { NS } \\
<0.0001\end{array}$ \\
\hline Cholesterol $(\mathrm{mmol} / \mathrm{l})$ & $\begin{array}{l}\mathrm{M} \\
\mathrm{F}\end{array}$ & $\begin{array}{l}6.11 \pm 1.2 \\
6.34 \pm 1.5\end{array}$ & $\begin{array}{l}6.51 \pm 1.2 \\
6.21 \pm 1.3\end{array}$ & $\begin{array}{l}6.57 \pm 1.1 \\
6.48 \pm 1.2\end{array}$ & $\begin{array}{l}6.69 \pm 1.1 \\
6.87 \pm 1.3\end{array}$ & $\begin{array}{l}0.0004 \\
0.0003\end{array}$ \\
\hline HDL chol (mmol/l) & $\begin{array}{l}\mathrm{M} \\
\mathrm{F}\end{array}$ & $\begin{array}{l}1.34 \pm 0.3 \\
1.66 \pm 0.3\end{array}$ & $\begin{array}{l}1.34 \pm 0.3 \\
1.64 \pm 0.4\end{array}$ & $\begin{array}{l}1.35 \pm 0.4 \\
1.61 \pm 0.4\end{array}$ & $\begin{array}{l}1.25 \pm 0.3 \\
1.58 \pm 0.4\end{array}$ & $\begin{array}{l}\text { NS } \\
\text { NS }\end{array}$ \\
\hline Triglyceride $^{a}(\mathrm{mmol} / \mathrm{l})$ & $\mathrm{F}$ & $\begin{array}{l}0.95 \\
(0.9-1.0)\end{array}$ & $\begin{array}{l}0.97 \\
(0.9-1.1)\end{array}$ & $\begin{array}{l}1.08 \\
(1.0-1.2)\end{array}$ & $\begin{array}{l}1.23 \\
(1.1-1.3)\end{array}$ & $<0.0001$ \\
\hline Systolic blood pressure $(\mathrm{mm} \mathrm{Hg})$ & $\begin{array}{l}\mathrm{M} \\
\mathrm{F}\end{array}$ & $\begin{array}{l}129.7 \pm 16.1 \\
120.3 \pm 14.6\end{array}$ & $\begin{array}{l}131.7 \pm 17.9 \\
125.0 \pm 14.2\end{array}$ & $\begin{array}{l}128.8 \pm 15.0 \\
129.0 \pm 17.4\end{array}$ & $\begin{array}{l}133.9 \pm 16.0 \\
129.8 \pm 17.8\end{array}$ & $\begin{array}{l}\text { NS } \\
<0.0001\end{array}$ \\
\hline Diastolic blood pressure $(\mathrm{mm} \mathrm{Hg})$ & $\begin{array}{l}\mathrm{M} \\
\mathrm{F}\end{array}$ & $\begin{array}{r}79.0 \pm 10.5 \\
73.4 \pm 8.6\end{array}$ & $\begin{array}{l}81.3 \pm 12.5 \\
75.4 \pm 8.7\end{array}$ & $\begin{array}{l}78.5 \pm 9.4 \\
78.5 \pm 11.1\end{array}$ & $\begin{array}{l}82.2 \pm 10.4 \\
77.7 \pm 10.3\end{array}$ & $\begin{array}{l}\text { NS } \\
0.0002\end{array}$ \\
\hline
\end{tabular}

Data are arithmetic mean \pm SD and a geometric mean (95\% confidence interval)

crease lipolysis [12] although whether smoking alters NEFA suppression during an oral glucose tolerance test (OGTT) is uncertain. The aims of this study were to: 1) determine the effects of NEFAs on triglyceride concentrations in the presence of insulin resistance and/or insulin deficiency and: 2) determine if increased triglyceride concentrations associated with smoking were attributable to increased NEFAs, in subjects who fulfilled World Health Organization criteria for normal glucose tolerance by OGTT.

\section{Subjects and methods}

Study design and subjects. The Isle of Ely Diabetes Project is a prospective population-based study of the aetiology and pathogenesis of NIDDM. Subjects for the study were recruited from a general practice register in Ely, Cambridgeshire, UK. The methods used in this study have previously been described in detail [13]. Briefly, a letter of invitation was sent to a random selection of patients not previously known to have diabetes, between the ages of 40 and 65 years at time of recruitment. Of the 1571 subjects invited, 1156 (74\%) participated and subjects taking oral contraceptives or hormone replacement therapy were not excluded from the study. After a 14-h fast subjects attended a clinical examination which included a dietary and medical questionnaire, anthropometric measurements and an OGTT. The analysis in this report was restricted to the 883 subjects with normal glucose tolerance and subjects with either newly-diagnosed NIDDM or impaired glucose tolerance were excluded from the analysis. Smoking and alcohol consumption were assessed using Health and Lifestyle Survey study criteria [14].
Physical measurements. Anthropometric measurements (height, weight, waist and hip circumferences) were taken without shoes and in light clothing. Body mass index (BMI) was calculated as weight $(\mathrm{kg})$ divided by height (m) squared. Waist circumference was measured at the mid-point between the inferior border of the costal margin and the anterior superior iliac spine and hip circumference at the level of the greater trochanters.

Oral glucose tolerance test and biochemical analyses. The OGTT consisted of a $75 \mathrm{mg}$ oral glucose challenge with collection of venous blood samples at baseline, $30 \mathrm{~min}$ and $120 \mathrm{~min}$. Samples of sera and plasma were immediately separated, kept on ice and stored at $-70^{\circ} \mathrm{C}$ within $4 \mathrm{~h}$. Plasma glucose was measured by a hexokinase method [15] and triglyceride measured using the RA 1000 (Bayer Diagnostics, Basingstoke, UK), with a standard enzymatic method. Plasma insulin level was determined by two-site immunometric assays with either ${ }^{125} \mathbf{I}$ or alkaline phosphatase labels $[16,17]$. Insulin concentrations were measured in baseline, $30-\mathrm{min}$ and 120 -min samples. The 30 -min insulin increment was included in the analysis and was calculated by dividing the difference between 30 -min insulin and fasting insulin concentrations by the 30 -min glucose concentration [10]. WHO criteria [18] were used to identify subjects with diabetes (fasting plasma glucose $\geq 7.8 \mathrm{mmol} / \mathrm{l}$ or $2-\mathrm{h}$ glucose $\geq 11.1 \mathrm{mmol} / \mathrm{l})$, impaired glucose tolerance $(2-\mathrm{h}$ glucose between $7.8-11.1 \mathrm{mmol} / \mathrm{l})$ and normal glucose tolerance (2-h glucose $<7.8 \mathrm{mmol} / \mathrm{l}$ ).

Plasma NEFA measurements were determined enzymatically based on the activity of acyl-CoA synthetase (Boehringer Mannheim, Lewes, Sussex, UK). The resultant acyl-Co A is oxidised to yield hydrogen peroxide which is measured colorimetrically [19]. The assay had a between-assay coefficient of variation of $10 \%$ at $0.40 \mathrm{mmol} / 1$ and $6 \%$ between 1.2 and $2.3 \mathrm{mmol} / \mathrm{l}$. NEFA concentrations were measured in baseline, 
Table 2. Insulin and NEFA concentrations in subjects grouped by gender and 120-min plasma glucose

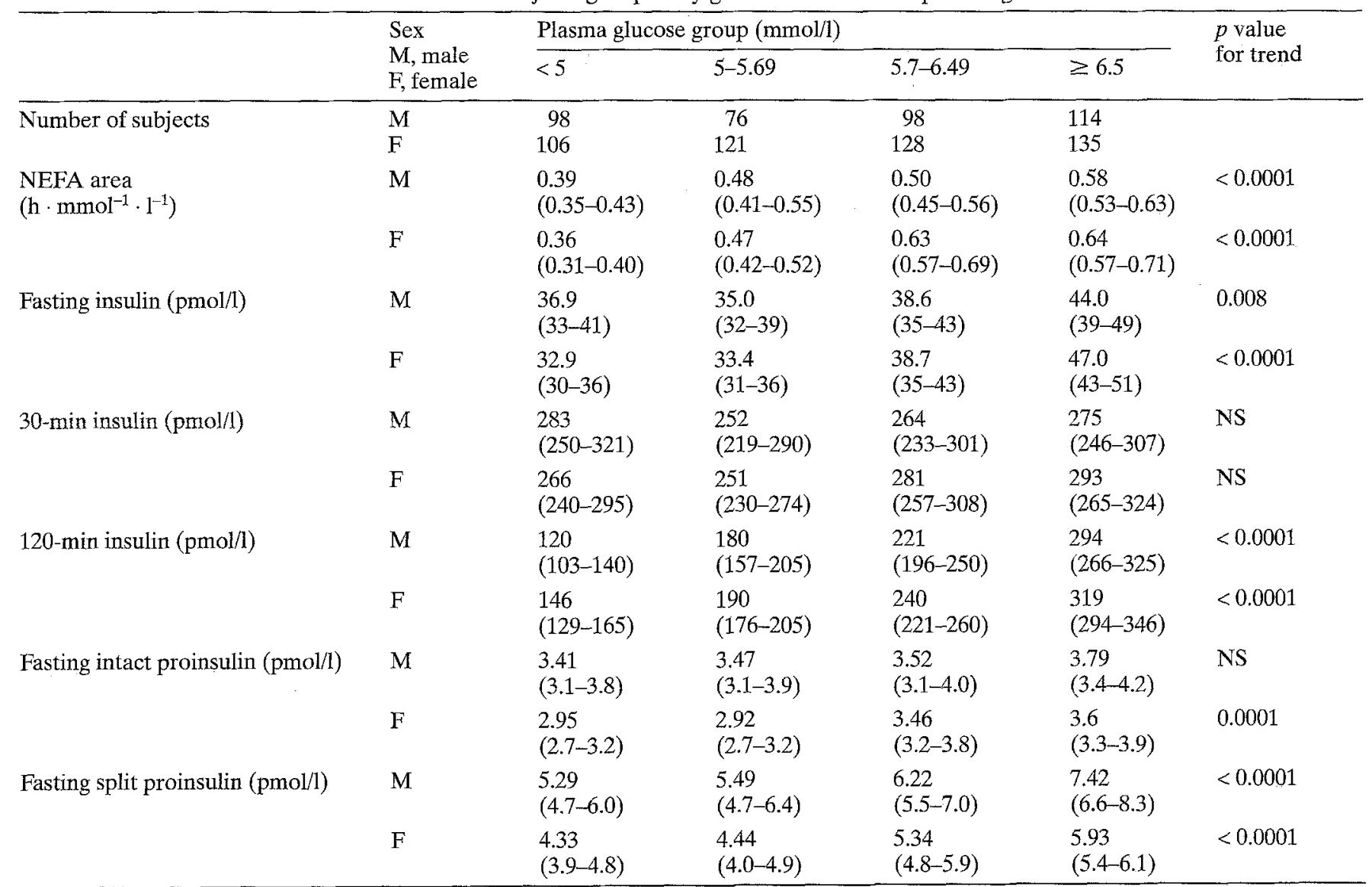

Data are geometric mean ( $95 \%$ confidence interval)

30-min and 120-min samples. NEFA area was also included in the analysis as a measure of both fasting NEFA concentration and suppression of NEFAs during the OGTT. NEFA area was calculated as the area under the trapezium described by the NEFA measurements at time 0,30 and $120 \mathrm{~min}$. The units of this measure are $\mathrm{h} \cdot \mathrm{mmol}^{-1} \cdot \mathrm{l}^{-1}$. The percentage of NEFA suppression was calculated over the first $30 \mathrm{~min}$ of the OGTT. This value was obtained by subtracting the 30 -min NEFA concentration from the fasting NEFA concentration and dividing the resulting value by the fasting NEFA concentration. The number obtained was then expressed as a percentage.

\section{Statistical analysis}

The means of the baseline variables are presented in Tables 1 and 2 , stratified by gender and quartile of plasma glucose at 120 min. Arithmetic means ( \pm SD) are presented where the underlying variable is normally distributed and geometric mean (and $95 \%$ confidence interval) where the distribution of a variable is skewed (Table 3 ). The $Z$ test was used to compare means between genders within each quartile of plasma glucose concentration. Percentages of NEFA suppression for men and women were compared using a Mann-Whitney Utest. Spearman rank correlation coefficients (Table 4) were derived to show the relationship between variables stratified by category for non-smokers, ex-smokers and current smokers. Finally multiple regression models were derived for men and women separately to explain variation in triglyceride concentrations, variation in 120-min glucose concentrations and varia- tion in HDL cholesterol concentrations. The following variables were considered for the triglyceride models; age, BMI, waist-hip ratio (WHR), smoking, alcohol intake, 120-min glucose level, NEFA area, fasting insulin and insulin increment. The same variables (excluding 120 -min glucose level) were considered for the 120 -min plasma glucose model and the same variables including triglyceride were considered for the HDL cholesterol models. For each variable in the final model the standardised $\beta$ coefficient and its significance are given (Tables $4-6$ ). The overall adjusted $R^{2}$ for each model allows comparison between models that include different numbers of explanatory variables. In these analyses the smoking category was coded for by a pair of binary indicator variables labelled s1 and s2 [20]. An indicator variable allows comparison between categories in a multiple regression analysis without imposing an artificial order on these groups. In this instance two variables $s 1$ and $s 2$ are needed to describe the three categories: non-smokers $(0,0)$, ex-smokers $(1,0)$ and smokers $(0,1)$.

\section{Results}

A total of 389 men and 494 women were identified with normal glucose tolerance as defined by WHO criteria. In order to determine if altered NEFA suppression and features normally associated with the IRS were affected by plasma glucose concentrations, subjects were divided into four groups on the basis 
Table 3. Anthropometric measures, biochemical results and smoking status

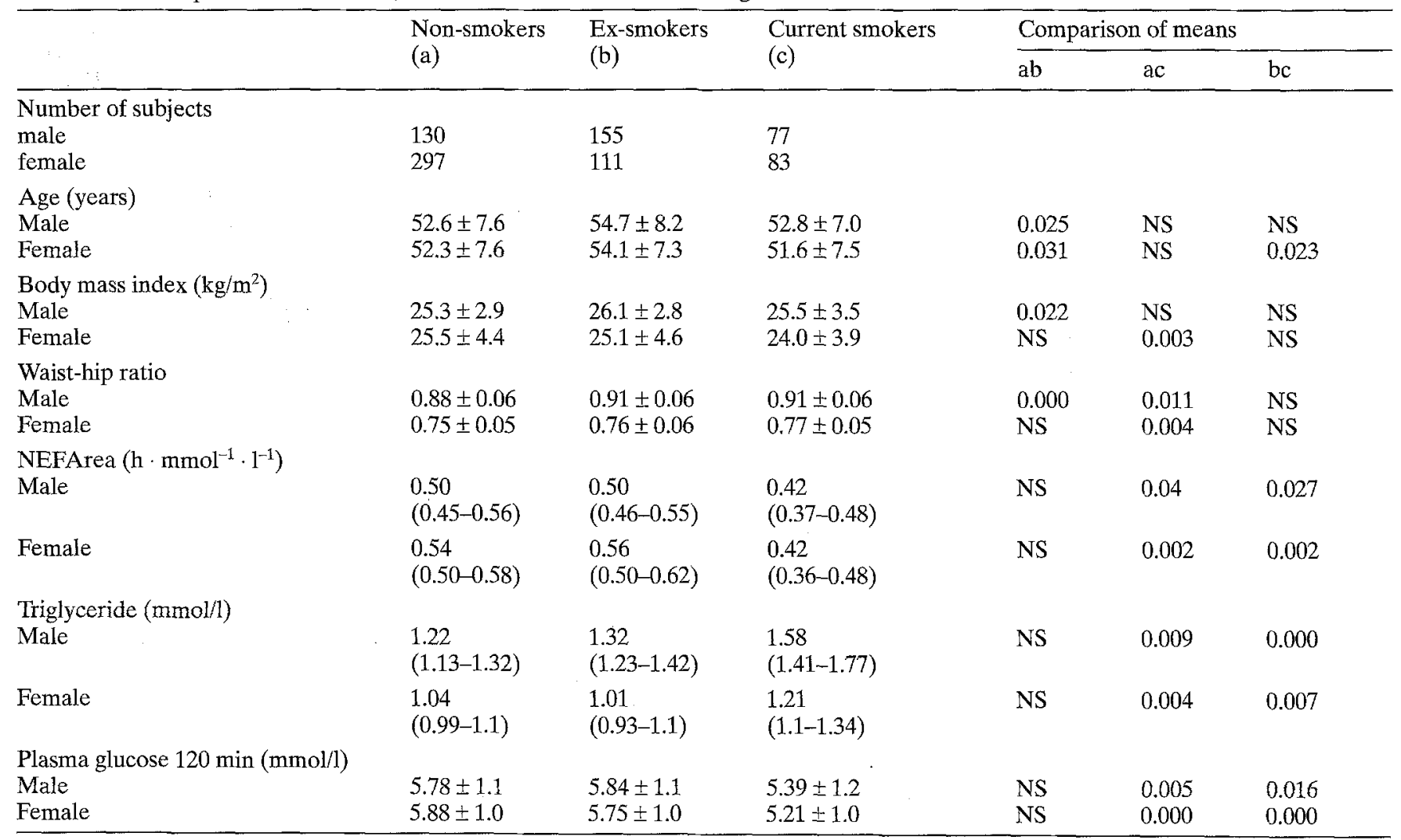

Data are arithmetic mean \pm SD or geometric mean (95\% confidence interval) as appropriate

Table 4. Spearman rank correlation matrices by smoking category and gender

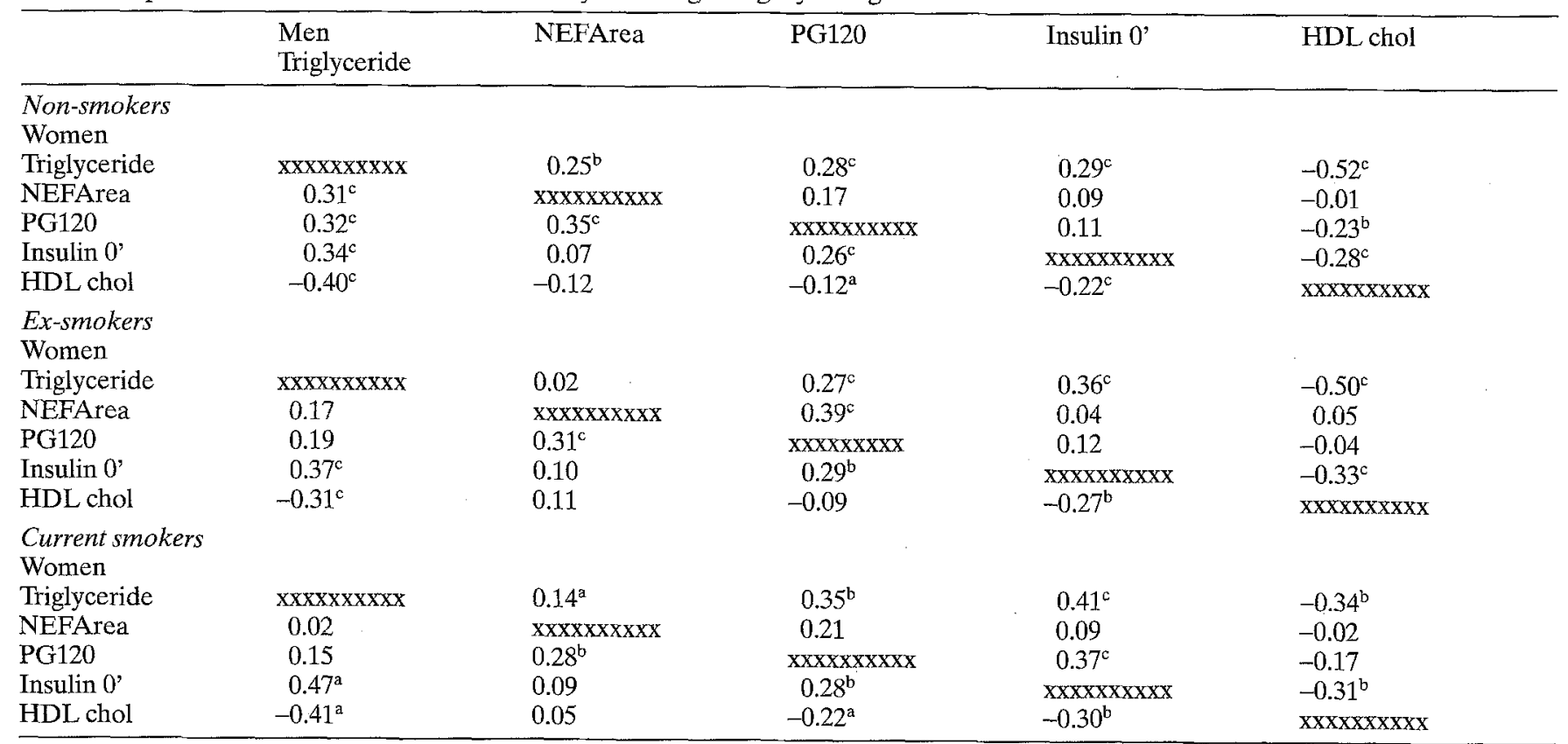

Results are Spearman rank correlation coefficients (significance); ${ }^{\mathrm{a}} p<0.05 ;{ }^{\mathrm{b}} p<0.01 ;{ }^{\mathrm{c}} p<0.001 ;$ PG120, Plasma glucose at $120 \mathrm{~min}(\mathrm{mmol} / \mathrm{l})$; Insulin 0', fasting insulin concentration (pmol/1); HDL chol, HDL cholesterol (mmol/1) 
Table 5. Results of multiple regression analysis with serum triglyceride as the dependent variable and independent variables as listed

\begin{tabular}{|c|c|c|c|c|c|c|}
\hline & \multicolumn{3}{|l|}{ Males } & \multicolumn{3}{|c|}{ Females } \\
\hline & $\mathrm{B}$ & $\beta$ & $p$ & $\mathrm{~B}$ & $\beta$ & $p$ \\
\hline $\begin{array}{l}\text { Independent variable } \\
\text { s1 } \\
\text { s2 }\end{array}$ & $\begin{array}{l}0.05 \\
0.40\end{array}$ & $\begin{array}{l}0.03 \\
0.20\end{array}$ & $\begin{array}{l}\text { NS } \\
0.001\end{array}$ & $\begin{array}{r}-0.12 \\
0.21\end{array}$ & $\begin{array}{r}-0.08 \\
0.13\end{array}$ & $\begin{array}{l}\text { NS } \\
0.005\end{array}$ \\
\hline Total alcohol consumption (units/week) & 0.00 & -0.01 & NS & 0.00 & -0.01 & NS \\
\hline Age (years) & -0.01 & -0.05 & NS & 0.02 & 0.21 & $<0.0001$ \\
\hline NEFArea $\left(h \cdot \mathrm{mmol}^{-1} \cdot \mathrm{l}^{-1}\right)$ & 0.36 & 0.12 & 0.02 & 0.22 & 0.12 & 0.005 \\
\hline Body mass index $\left(\mathrm{kg} / \mathrm{m}^{2}\right)$ & 0.03 & 0.12 & NS & 0.03 & 0.21 & $<0.0001$ \\
\hline Waist-hip ratio & 2.36 & 0.17 & 0.01 & 2.56 & 0.22 & $<0.0001$ \\
\hline Model adjusted $R^{2}$ & 0.09 & & & 0.22 & & \\
\hline
\end{tabular}

s1 and $\mathrm{s} 2$ are dummy variables grouping subjects into non-smokers, ex-smokers and current smokers

Table 6. Results of multiple regression analysis with serum triglyceride as the dependent variable and independent variables as listed

\begin{tabular}{|c|c|c|c|c|c|c|}
\hline & Males & & & Females & & \\
\hline & $\mathrm{B}$ & $\beta$ & $p$ & $\mathrm{~B}$ & $\beta$ & $p$ \\
\hline $\begin{array}{l}\text { Independent variable } \\
\text { s1 } \\
\text { s2 }\end{array}$ & $\begin{array}{l}0.05 \\
0.43\end{array}$ & $\begin{array}{l}0.03 \\
0.12\end{array}$ & $\begin{array}{l}\text { NS } \\
0.0005\end{array}$ & $\begin{array}{r}-0.11 \\
0.25\end{array}$ & $\begin{array}{r}-0.08 \\
0.15\end{array}$ & $\begin{array}{l}\text { NS } \\
0.001\end{array}$ \\
\hline Total alcohol consumption (units/week) & 0.00 & 0.00 & NS & 0.00 & -0.01 & NS \\
\hline Age (years) & 0.00 & -0.05 & NS & 0.016 & 0.20 & $<0.0001$ \\
\hline Plasma glucose $120 \mathrm{~min}(\mathrm{mmol} / \mathrm{l})$ & 0.11 & 0.15 & 0.008 & 0.08 & 0.13 & 0.004 \\
\hline Body mass index $\left(\mathrm{kg} / \mathrm{m}^{2}\right)$ & 0.027 & 0.10 & NS & 0.026 & 0.18 & 0.0001 \\
\hline Waist-hip ratio & 2.21 & 0.16 & 0.02 & 2.43 & 0.21 & $<0.0001$ \\
\hline NEFArea & 0.256 & 0.09 & NS & 0.15 & 0.08 & NS \\
\hline Model adjusted $R^{2}$ & 0.11 & & & 0.24 & & \\
\hline
\end{tabular}

s1 and s2 are dummy variables grouping subjects into non-smokers, ex-smokers and current smokers

of their 120-min plasma glucose concentrations (Tables 1 and 2). In these analyses $p$-values were calculated to determine if significant trends existed across the four groups. Tables 1 and 2 include complete data on 876 of 883 subjects with normal glucose tolerance.

NEFA area (a marker of NEFA suppression) increased with increasing plasma glucose in both sexes and fasting NEFA concentrations were increased in women compared with men (Fig. 1). In order to determine if NEFA suppression was different between the sexes the percentage of NEFA suppression was calculated for men and women during the first $30 \mathrm{~min}$ of the OGTT. In men the median percentage suppression during the first 30 min was $2.4 \%$ whereas in women the median percentage suppression was $16.7 \%$ $(p<0.001)$.

To determine if there were differences between triglyceride concentrations in individuals who were current smokers, ex-smokers and non-smokers, triglyceride concentrations were compared in the three groups (Table 3 ). Spearman rank correlation coefficients were calculated for triglyceride, NEFA area, 120-min plasma glucose and fasting insulin for both men and women who were smokers, ex-smokers and non-smokers (Table 4).

In order to investigate associations between possible explanatory variables and triglyceride concentrations multiple regression analyses were undertaken. In the first regression model with plasma triglyceride as the dependent variable, NEFA area, WHR and cigarette smoking were independently associated with triglyceride concentrations in both sexes (Table 5). As it was likely that NEFA suppression was affected by insulin concentrations this regression model was repeated with fasting insulin (as a measure of insulin resistance) and 30-min insulin increment (as a measure of insulin secretion) added to the model. In this model NEFA area was still independently associated with triglyceride levels (for men $\beta$ coefficient $0.15, p<0.01$; and for women $\beta$ coefficient 0.08 , $p<0.05)$. Fasting insulin was independently associated with triglyceride levels in both sexes (for men $\beta$ coefficient $0.18, p<001$; and for women $\beta$ coefficient $0.3, p<0.001$ ) whereas no association with 30 -min insulin increment was found in either sex. Adding both 


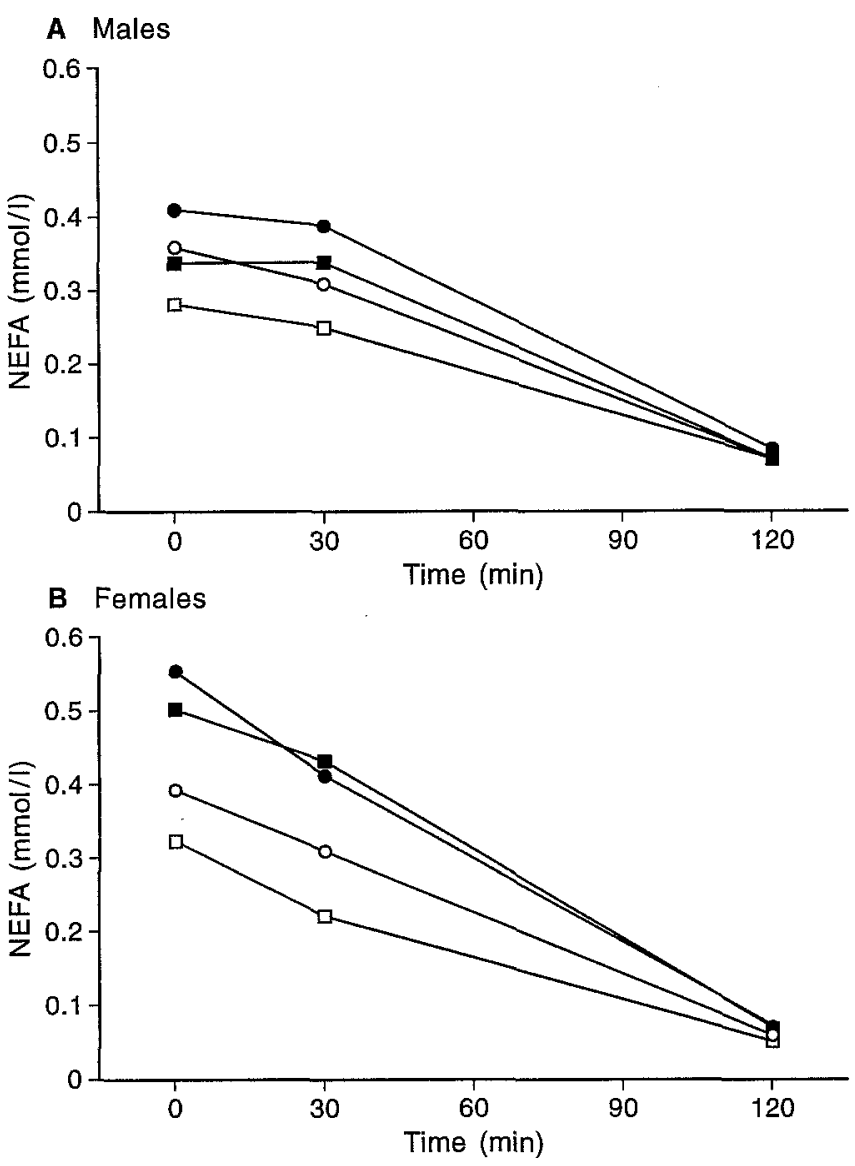

Fig. 1 A, B. Plasma NEFA concentrations at 0, 30 and $120 \mathrm{~min}$ after administration of $75-\mathrm{g}$ oral glucose in males $(\mathbf{A})$ and females (B), stratified by 120 -min post-load plasma glucose concentration (PG). $-\square-\mathrm{PG}<5 ;-\mathrm{O}, \mathrm{PG}=5-5.69 ;-\square, \mathrm{PG}=5.7$ $-6.49 ;-\bullet, \mathrm{PG} \geq 6.5 \mathrm{mmol} / \mathrm{l}$

fasting insulin and insulin increment to this model did not adjust the $R^{2}$ value for either sex.

To determine if plasma glucose affected the independent association between NEFA area (as a marker of NEFA suppression) and triglyceride concentrations, 120-min plasma glucose was introduced into the regression model with plasma triglyceride as the dependent variable. In this analysis fasting insulin and 30-min insulin increment were excluded from the model (Table 6). The results show that the strength of the association between triglyceride and NEFA area was reduced and that glucose concentration was independently associated with triglyceride concentration in both sexes. Therefore, to further investigate the association between 120-min plasma glucose and NEFA area, regression analysis was undertaken with 120-min glucose as the dependent variable (Table 7). The same analysis was repeated excluding NEFA area from the model to determine if the strength of the associations between insulin parameters (as markers of insulin resistance and insulin deficiency) and 120-min plasma glucose were altered. In men the adjusted $R^{2}$ changed from 0.13 to 0.09 whereas in women the adjusted $R^{2}$ changed from 0.23 to 0.16 indicating that NEFA suppression explained some of the variation in 120-min glucose independently of insulin concentrations.

HDL cholesterol was inversely associated with triglyceride levels in non-smokers, ex-smokers and current smokers (Table 4). To examine the association between HDL cholesterol and triglyceride, regression analysis was undertaken with HDL cholesterol as the dependent variable. In men the adjusted $R^{2}$ was 0.24 and triglyceride (inversely) and alcohol were the only factors independently associated with HDL $(\beta$ coefficients -0.37 and 0.24 , respectively, both $p<0.0001$ ). In women the adjusted $R^{2}$ was 0.22 and, triglyceride (inversely), WHR (inversely) and age were independently associated with HDL $(\beta$ coefficients $-0.35,-0.19$ and 0.23 , all $p<0.0001$ ).

An analysis of anthropometric measures and biochemical results undertaken in non-smokers, exsmokers and current smokers showed that there were differences in metabolic risk factors between the groups (Table 3). To determine the effect of smoking on triglyceride concentrations, regression analysis was undertaken with triglyceride as the dependent variable in two different models (Tables 5 and 6). As differences in anthropometric and biochemical measures existed between groups according to smoking status, the dummy variables $\mathrm{s} 1$ and $\mathrm{s} 2$ were introduced into these models to represent subjects grouped into non-smokers, ex-smokers and current smokers. The results show that smoking was associated with triglyceride levels independently of alcohol consumption, age, plasma glucose, BMI, WHR and NEFA area. To determine whether the effect of smoking on triglyceride concentrations was mediated through changes in NEFA suppression regression analysis was undertaken with NEFA area as the dependent variable and the same dummy variables s1 and s2 representing smoking category. This analysis showed that there was no independent association between smoking and NEFA area in both sexes. Fasting insulin and 30-min insulin increment were also introduced into the regression model with triglyceride as the dependent variable (i.e., Table 5) to determine whether insulin secretion or insulin resistance interacted with smoking to affect plasma triglyceride concentrations. In this analysis smoking was still independently associated with triglyceride levels in both sexes (for men $\beta$ coefficient 0.23 , $p<001$; and for women $\beta$ coefficient $0.14, p=0.001$ ), indicating that addition of insulin parameters to the model did not explain any more of the variation in plasma triglyceride as the model adjusted $R^{2}$ values remained unchanged. 
Table 7. Results of multiple regression analysis with 120 -min plasma glucose as the dependent variable and independent variables as listed

\begin{tabular}{|c|c|c|c|c|c|c|}
\hline & \multicolumn{3}{|l|}{ Males } & \multicolumn{3}{|l|}{ Females } \\
\hline & $\mathrm{B}$ & $\beta$ & $p$ & $\overline{\mathrm{B}}$ & $\beta$ & $p$ \\
\hline $\begin{array}{l}\text { Independent variable } \\
\text { s1 } \\
\text { s2 }\end{array}$ & $\begin{array}{r}0.04 \\
-0.29\end{array}$ & $\begin{array}{r}0.02 \\
-0.10\end{array}$ & $\begin{array}{l}\text { NS } \\
\text { NS }\end{array}$ & $\begin{array}{l}-0.11 \\
-0.40\end{array}$ & $\begin{array}{l}-0.05 \\
-0.15\end{array}$ & $\begin{array}{l}\text { NS } \\
0.001\end{array}$ \\
\hline Total alcohol consumption (units/week) & -0.01 & -0.05 & NS & 0.00 & -0.01 & NS \\
\hline Age (years) & 0.01 & 0.05 & NS & 0.013 & 0.10 & 0.03 \\
\hline Body mass index $\left(\mathrm{kg} / \mathrm{m}^{2}\right)$ & 0.05 & 0.14 & 0.03 & 0.036 & 0.15 & 0.002 \\
\hline Waist-hip ratio & 1.43 & 0.08 & NS & 1.07 & 0.06 & NS \\
\hline NEFArea $\left(\mathrm{h} \cdot \mathrm{mmol}^{-1} \cdot \mathrm{l}^{-1}\right)$ & 0.87 & 0.22 & $<0.0001$ & 0.83 & 0.27 & $<0.0001$ \\
\hline Fasting insulin (pmol/1) & 0.003 & 0.09 & NS & 0.007 & 0.17 & 0.0005 \\
\hline Insulin increment & -0.01 & -0.17 & 0.001 & -0.01 & -0.14 & 0.002 \\
\hline Model adjusted $R^{2}$ & 0.13 & & & 0.23 & & \\
\hline
\end{tabular}

$\mathrm{s} 1$ and $\mathrm{s} 2$ are dummy variables grouping subjects into non-smokers, ex-smokers and current smokers

\section{Discussion}

The results of this study show that there is a clustering of risk factors normally associated with IRS in subjects within the highest quartile of 120 -min glucose concentrations. Therefore, a sub-group of individuals who satisfy the WHO criteria for normal glucose tolerance may be at increased risk from IHD because they have many of the features normally associated with IRS. This supports the concept of treating glucose tolerance as a continuous variable and suggests that placing an individual in a group entitled "normal glucose tolerance" may disguise the fact that an individual is still at risk from IHD. These results also show that there were marked differences between subjects grouped according to quartiles of $120-\mathrm{min}$ glucose in NEFA suppression (as measured by NEFA area) in both sexes. Individuals of both sexes in the top quartile had markedly increased NEFAs compared to individuals in the bottom quartile and failure to suppress NEFAs during OGTT and an increased WHR were both associated with raised plasma triglyceride concentrations. At 120 min NEFAs were completely suppressed and although in our study the 30-min measurement helped to determine differences in NEFA suppression between the groups it is likely that a more accurate determination of NEFA suppression could be achieved by additional measurements around the 30 -min time point. The percentage of NEFA suppression during the first $30 \mathrm{~min}$ of the OGTT showed that in women NEFA suppression was more marked than in men and greater NEFA suppression may contribute to lower triglyceride concentrations in women. We have shown previously that NEFA suppression was reduced during the first $30 \mathrm{~min}$ of an OGTT in women with newly-diagnosed NIDDM [10] compared to women with normal glucose tolerance and it is possible that (in women) both diabetes and a male pat- tern of fat distribution reduce rapid suppression of NEFAs, resulting in increased plasma triglyceride concentrations.

In order to study associations between 120-min glucose, insulin resistance, relative insulin deficiency and NEFA area, regression analysis was undertaken with 120 -min plasma glucose as the dependent variable. Fasting insulin was included in the model as a surrogate for insulin resistance [21], the 30-min insulin increment was included as a surrogate for insulin deficiency $[10,22]$ and NEFA area was included as a surrogate for NEFA suppression [10]. The results showed that NEFA area was strongly associated with 120 -min glucose in the regression analysis. As expected both fasting insulin and 30-min insulin increment were independently associated with 120 min plasma glucose. Exclusion of NEFA area from the analysis weakened the model and explained less of the variation in glucose concentrations indicating that insulin concentrations alone did not explain all of the variation in 120-min glucose. These results support the notion that increased NEFA concentrations may worsen insulin resistance through the Randle cycle [23]. Recently it has been shown that NEFAs decreased glycogen synthesis and carbohydrate oxidation and reduced the insulin-mediated decrease in hepatic glucose output [24]. Increased NEFAs may also be intimately linked to increased triglyceride levels since NEFAs increase hepatic triglyceride synthesis and VLDL production $[7,8]$ and we have also shown that NEFAs may increase hepatic triglyceride secretion by reduction of the inhibitory effect of insulin on hepatic triglyceride secretion [8]. This latter effect of NEFAs has recently been shown to occur in vivo [25]. In individuals with normal glucose tolerance VLDL production increased in response to an increase in plasma NEFAs. Infusion of insulin-reduced VLDL secretion and the insulin-induced decrease in VLDL production was also diminished by 
concomitant administration of fatty acid. Thus, the negative effect of NEFAs on insulin action appears to represent another aspect of NEFAs ability to act as insulin antagonists as originally proposed with the concept of the Randle cycle.

When fasting insulin level (a marker of insulin resistance) was introduced into the regression model with triglyceride as the dependent variable the independent association of NEFA area with triglyceride concentration remained, suggesting that insulin resistance to glucose disposal alone does not determine NEFA concentrations. Increased plasma NEFA concentrations may also serve as a marker for worsening glucose tolerance, although failure of insulin to adequately suppress hormone-sensitive lipase probably does not explain all of the association between glucose and NEFA area, as catecholamines also affect lipolysis. It has been shown that in subjects with increased WHR, catecholamine-induced lipolysis was reduced in subcutaneous adipose tissue biopsies from male subjects with IRS [26].

Age was a major determinant of triglyceride levels in females only. Since age was an unimportant explanatory variable in men a possible effect of the menopause is suggested. The mean age of women in the lowest quartile of triglyceride levels was 49.4 years and in the highest quartile was 55.6 years. The menopausal status of our subjects was not known but it is likely that some of the individuals from the lowest quartile were pre-menopausal and those from the highest quartile are post-menopausal as the average age of menopause in the UK is 50 years [27]. Although our data are cross-sectional they suggest that the menopause may affect triglyceride levels independently of age, as age was not an independent determinant of triglyceride concentrations in men. This observation accords with recent work showing that triglyceride concentrations increased independently of age with the menopause [28]. The mechanism causing increased triglyceride concentrations is unknown and whether menopause or age directly affects NEFA suppression is uncertain. Recently it has been shown that menopause increased fasting NEFAs in Asian women but no effect of menopause on fasting NEFAs was shown in Caucasian women [11].

Smoking was also associated with increased plasma triglyceride concentrations. Smoking was associated with a higher WHR in both sexes and a higher BMI in women but not in men. Recently it has been shown that an immediate effect of smoking is to increase plasma NEFA concentrations by increasing NEFA entry into the circulation and by increasing hepatic re-esterification [12]. Our results showed that in the regression analysis after adjustment, smoking was not independently associated with any alteration of NEFA suppression. Subjects in our study were asked not to smoke after 22.00 hours during the evening preceding the day of the test and were not allowed to smoke until the test was completed. Consequently, the results of our study are not directly comparable to those of Hellerstein et al. [12], as it is likely that any independent effect of smoking on triglyceride in our study would be attributable to a longerterm effect. Since the regression analysis with triglyceride as the dependent variable showed that the effect of smoking on triglyceride in current smokers was different from that in ex-smokers, it is likely that the effect of smoking on triglyceride concentration is a medium-term effect and does disappear with time. Our results showed that NEFA area was lower in current smokers and ex-smokers compared to control subjects but it is likely that this is attributable to lower plasma glucose concentrations in smokers and exsmokers as glucose levels were strongly associated with NEFA area. At present we are unable to explain the lower glucose concentrations in smokers and ex-smokers compared to non-smokers. Despite the lower plasma glucose concentrations and lower NEFA areas in smokers compared to non-smokers, triglyceride levels were higher in this group compared to control subjects. Regression analysis showed that the effect of smoking on triglycerides was independent of alcohol consumption, age, 120min plasma glucose, BMI, WHR and NEFA area and therefore suggests that the effect of smoking is mediated by an alternative unknown mechanism.

In conclusion, $53(6 \%)$ of the subjects ( 41 men and 12 women) participating in this study had HDL cholesterol concentrations of below $1.02 \mathrm{mmol} / \mathrm{l}$ and were in the highest quartile of triglyceride concentration (i. e., $\geq 1.8 \mathrm{mmol} / 1$ in men and $\geq 1.4 \mathrm{mmol} / 1$ in women). The Framingham study has shown that similar, relatively mild perturbations of both lipids were associated with a marked increase in IHD risk, that according to Castelli [4], places these individuals on the "fast track to atherosclerotic disease". Our data show that in these "at-risk" individuals plasma glucose was increased compared to the rest of the sample, there was a marked decrease in NEFA suppression and these two associated abnormalities may have significant implications for triglyceride concentrations in such subjects. According to the 1991 census data there are approximately 14.6 million individuals between the ages of 40 and 65 years in the UK [29]; $6 \%$ of 14.6 million is 880,000 at-risk individuals. Attempts to identify these individuals may be beneficial as simple measures to reduce abdominal girth, increase physical activity and stop smoking may significantly reduce their risk of IHD.

Acknowledgements. This study was supported by grants from the BDA and MRC, Bayer Diagnostics, Corda and Lilley Research Laboratories. C.D.B. is an MRC Clinician Scientist. The technical assistance of R. Beck, L. Cox, T. Elsey, N.D. Martensz, B. Mission, M. Sheldon and A. F. M. Tullock is grate- 
fully acknowledged. We would like to thank D. Brown, P. Clark, B. Cox, J. M. Lipscombe, M. Quinn, S. Farmer, L. Koncewicz, C. Palmer, H. Shanassy and T. Wang for their assistance in the field work and data entry. Finally we are grateful to all the volunteers who participated in the study and to Dr. J. Shackleton and his colleagues at St. Mary's Surgery, Ely.

\section{References}

1. Reaven GM (1988) The role of insulin resistance in human disease. Diabetes 37: 1595-1607

2. Uusitupa M, Siitonen O, Aro A, Pyörälä K (1985) Prevalence of coronary heart disease, left ventricular failure and hypertension in middle-aged, newly-diagnosed type 2 (non-insulin-dependent) diabetic subjects. Diabetologia 28: $22-27$

3. Stern MP, Haffner SM (1991) Dyslipidemia in type II diabetes. Diabetes Care 14: 1144-1159

4. Castelli WP (1992) Epidemiology of triglycerides: a view from Framingham. Am J Cardiol 70: $3 \mathrm{H}-9 \mathrm{H}$

5. Ferrannini E, Haffner SM, Mitchell BD, Stern MP (1991) Hyperinsulinaemia: the key feature of a cardiovascular and metabolic syndrome. Diabetologia 34: 416-422

6. Durrington PN, Newton S, Weinstein DB, Steinberg D (1982) Effects of insulin and glucose on very low density lipoprotein triglyceride secretion by cultured rat hepatocytes. J Clin Invest 70: 63-73

7. Pullinger CR, North JD, Teng BB, Rifici VA, Ronhild de Brito AE, Scott J (1989) The apolipoprotein gene is constitutively expressed in HepG2 cells: regulation of secretion by oleic acid, albumin and insulin, and measurement of mRNA half life. J Lipid Res 30: 1065-1077

8. Byrne CD, Brindle NPJ, Wang TWM, Hales CN (1991) Interaction of non-esterified fatty acid and insulin in control of triacylglycerol secretion by HepG2 cells. Biochem J 280: 99-104

9. Bartlett SM, Gibbons GF (1988) Short and longer term regulation of very low density lipoprotein secretion by insulin, dexamethasone and lipogenic substrates in cultured hepatocytes. Biochem J 249: 37-43

10. Byrne CD, Wareham NJ, Brown DC et al. (1994) Hypertriglyceridaemia in subjects with normal and abnormal glucose tolerance: relative contributions of insulin secretion, insulin resistance and suppression of plasma non-esterified fatty acids. Diabetologia 37: 889-896

11. McKeigue PM, Laws A, Chen YD, Marmot MG, Reaven GM (1993) Relation of plasma triglyceride and apo B levels to insulin-mediated suppression of non-esterified fatty acids. Arterioscler Thromb 13: 1187-1192

12. Hellerstein MK, Benowitz NL, Neese RA et al. (1994) Effects of cigarette smoking and its cessation on lipid metabolism and energy expenditure in heavy smokers. J Clin Invest 93: $265-272$
13. Williams DRR, Wareham NJ, Brown DC et al. (1995) Undiagnosed glucose intolerance in the community: the Isle of Ely Diabetes Project. Diabet Med 12: 30-35

14. The Health and Lifestyle Survey: seven years on. (1993) Cox BD, Huppert FA, Whichelow MJ (eds) Dartmouth Publishing Co, Ltd., Aldershot, UK

15. Kunst A, Draeger B, Ziegenhorn J (1983) UV-methods with hexokinase and glucose-6-phosphate dehydrogenase. In: Bergmeyer HU (ed) Methods of enzymatic analysis, vol 6. Chemie, Deerfield, pp 163-172

16. Sobey WJ, Beer SF, Carrington CA et al. (1989) Sensitive and specific two site immunoradiometric assays for human insulin, proinsulin, 65-66 split and 32-33 split proinsulins. Biochem J 260: 535-541

17. Alpha B, Cox L, Crowther N, Clark PMS, Hales CN (1992) Sensitive amplified immunoenzymometric assays (IEMA) for human insulin and intact proinsulin. Eur J Clin Chem Biochem 30: 27-32

18. WHO study group (1985) Diabetes mellitus. Technical report series No 727. WHO, Geneva

19. Shimizu S (1980) Enzymatic determination of serum-free fatty acids: a colorimetric method. Anal Biochem 107: 193-198

20. Clayton D, Hills M (1993) Statistical models in epidemiology. Oxford University Press, Oxford

21. Laakso M (1993) How good a marker is insulin level for insulin resistance? Am J Epidemiol 137: 959-965

22. Phillips DIW, Clark PM, Hales CN, Osmond C (1994) Understanding oral glucose tolerance: comparison of glucose or insulin measurements during the oral glucose tolerance test with specific measurements of insulin resistance and insulin secretion. Diabet Med 11: 286-292

23. Randle PJ, Garland PB, Hales CN, Newsholme EA (1963) The glucose-fatty acid cycle, its role in insulin sensitivity and the metabolic disturbances of diabetes mellitus. Lancet I:785-789

24. Boden G, Chen X, Ruiz J, White JV, Rossetti L (1994) Mechanisms of fatty acid-induced inhibition of glucose uptake. J Clin Invest 93: 2438-2446

25. Lewis GF, Uffelman KD, Szeto LW, Weller B, Steiner G (1995) Interaction between fatty acids and insulin in the acute control of very low density lipoprotein production in humans. J Clin Invest 95: 158-166

26. Reynisdottir S, Ellerfeldt K, Wahrenberg H, Lithell H, Arner P (1994) Multiple lipolysis defects in the insulin resistance syndrome. J Clin Invest 93: 2590-2599

27. Khaw K-T (1992) The menopause and hormone replacement therapy. Postgrad Med J 68: 615-623

28. Stevenson JC, Crook D, Godsland IF (1993) Influence of age and menopause on serum lipids and lipoproteins in healthy women. Atherosclerosis $98: 83-90$

29. Mortality statistics, cause (1991) Review of the Registrar General on deaths by cause, sex and age, in England and Wales. OPCS Series DH2, no 18, HMSO, London 